\title{
Local Regeneration of Dentin-Pulp Complex Using Controlled Release of FGF-2 and Naturally Derived Sponge-Like Scaffolds
}

\author{
Chiaki Kitamura, ${ }^{1}$ Tatsuji Nishihara, ${ }^{2}$ Masamichi Terashita, ${ }^{3}$ \\ Yasuhiko Tabata, ${ }^{4}$ and Ayako Washio ${ }^{1}$ \\ ${ }^{1}$ Division of Pulp Biology, Operative Dentistry and Endodontics, Department of Cariology and Periodontology, Kyushu Dental College, \\ Manazuru 2-6-1, Kokurakita, Kitakyushu 803-8580, Japan \\ ${ }^{2}$ Division of Infections and Molecular Biology, Department of Health Promotion, Kyushu Dental College, Manazuru 2-6-1, Kokurakita, \\ Kitakyushu 803-8580, Japan \\ ${ }^{3}$ Division of Comprehensive Dentistry, Department of Clinical Communication and Practice, Kyushu Dental College, Manazuru 2-6-1, \\ Kokurakita, Kitakyushu 803-8580, Japan \\ ${ }^{4}$ Department of Biomaterials, Institute for Frontier Medical Sciences, Kyoto University, 53 Kawara-cho, Shogoin, Sakyo-ku, \\ Kyoto 606-8507, Japan \\ Correspondence should be addressed to Chiaki Kitamura, chi-aki-k@kyu-dent.ac.jp
}

Received 3 August 2011; Accepted 8 September 2011

Academic Editor: Kotaro Tanimoto

Copyright ( $\odot 2012$ Chiaki Kitamura et al. This is an open access article distributed under the Creative Commons Attribution License, which permits unrestricted use, distribution, and reproduction in any medium, provided the original work is properly cited.

\begin{abstract}
Restorative and endodontic procedures have been recently developed in an attempt to preserve the vitality of dental pulp after exposure to external stimuli, such as caries infection or traumatic injury. When damage to dental pulp is reversible, pulp wound healing can proceed, whereas irreversible damage induces pathological changes in dental pulp, eventually requiring its removal. Nonvital teeth lose their defensive abilities and become severely damaged, resulting in extraction. Development of regeneration therapy for the dentin-pulp complex is important to overcome limitations with presently available therapies. Three strategies to regenerate the dentin-pulp complex have been proposed; regeneration of the entire tooth, local regeneration of the dentinpulp complex from amputated dental pulp, and regeneration of dental pulp from apical dental pulp or periapical tissues. In this paper, we focus on the local regeneration of the dentin-pulp complex by application of exogenous growth factors and scaffolds to amputated dental pulp.
\end{abstract}

\section{Limitations of Conventional Therapy for Preservation of Dental Pulp}

Dental pulp is sometimes affected by external stimuli such as caries infection or traumatic injury. Preservation of dental pulp and maintenance of its viability are essential to avoid tooth loss, and dentists carry out restorative procedures with pulp capping to regulate inflammatory responses of dental pulp, or cement lining on a cavity floor to block external stimuli. Reversible damage induces pulp wound healing, and direct pulp capping and pulpotomy with calcium hydroxide are known to be effective to induce pulp wound healing mechanisms.

After external stimuli such as cavity preparation, apoptosis of pulp cells including odontoblasts is induced [1-5], followed by pulp wound healing including reactionary and reparative dentinogenesis. Reactionary dentin is formed by surviving odontoblasts, whereas reparative dentin is formed by odontoblast-like cells that are differentiated from pulp cells of residual dental pulp, resulting in a reduction in dental pulp size and vitality [6-8].

When the external damage to dental pulp induces irreversible changes of the pulp, dentists carry out pulpectomy. Generally, a root canal after pulpectomy is tightly filled with biomaterials such as gutta-percha to prevent reinfection by bacteria. However, a tooth without vital dental pulp has lost its defensive ability, which is often followed by the severe damage such as the progression of deep radicular caries or tooth facture, resulting in extraction of 
the tooth. Furthermore, a treated tooth is often reinfected by bacteria because of its complicated anatomical structure or inadequate treatment by a dentist, resulting in formation of a lesion around the root apex with bone resorption. The success rate of the endodontic retreatment is lower than that of pulpectomy [9-12]. To overcome these limitations of the present endodontic treatment, the preservation of dentinpulp complex is the clear strategy. However, when a dentin defect and the resultant exposure of dental pulp tissue reach a critical size, no treatments available are able to preserve and maintain the vitality of dental pulp. It is considered important to develop regeneration therapy for dental pulp or the dentin-pulp complex.

\section{Regeneration of the Dentin-Pulp Complex}

It is well known that growth factors, such as bone morphogenetic proteins (BMPs) and fibroblast growth factors (FGFs), stem cells, and scaffolds, are essential for tissue engineering to regenerate tissues [13]. During regeneration processes, stem cells differentiate into specific cells for tissue defects, growth factors such as BMPs and FGFs induce proliferation and differentiation of stem cells, and scaffolds with properties of extracellular matrix temporally support structures for cell growth, differentiation, and tissue formation. In studies to develop the regeneration therapy of the dentin-pulp complex, three strategies that utilize these essential three factors have been proposed; regeneration of the entire tooth, local regeneration of the dentin-pulp complex in dentin defect area from residual dental pulp, and regeneration of dental pulp from apical dental pulp or periapical tissues including the periodontal ligament and bone (Figure 1).

\subsection{Regeneration of Entire Tooth. Regeneration of the entire} tooth is accepted as a model of organ replacement and regeneration therapy. Recently, it was reported that tooth germs can be bioengineered using a three-dimensional organ-germ culture method, in which dental epithelial and mesenchymal cells isolated from tooth germs were cultured in threedimensional scaffolds for the replacement therapy. Scaffolds consisted of synthetic polymers such as poly (lactide-coglycolide) (PLGA) and bioceramics such as hydroxyapatite, tricalcium phosphate and calcium carbonate hydroxyapatite were examined in the three-dimensional organ-germ culture [14-21]. It was also reported that bioengineered teeth were generated from three-dimensionally arranged dental epithelial and mesenchymal cells in collagen gels by in vitro cell aggregate and manipulation method, and that the bioengineered tooth germ generated a structurally correct tooth showing penetration of blood vessels and nerve fibers in vivo transplantation into mouse maxilla, resulting in a successful fully functioning tooth replacement [22-25]. These bioengineered teeth, however, were reconstructed with dental epithelial and mesenchymal cells from genuine tooth germs. Further research will be needed to regenerate the entire tooth from other cell sources such as induced pluripotent stem (iPS) cells.

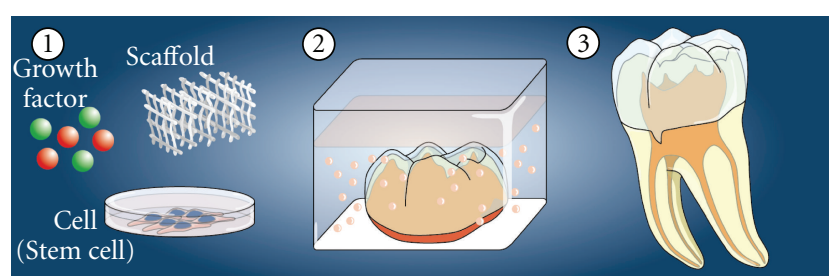

(a) Regeneration of the entire tooth

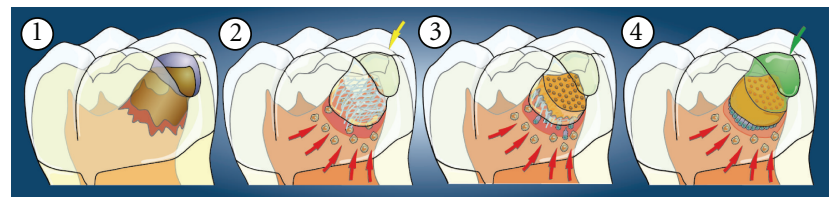

(b) Local regeneration of dentin-pulp complex from residual dental pulp

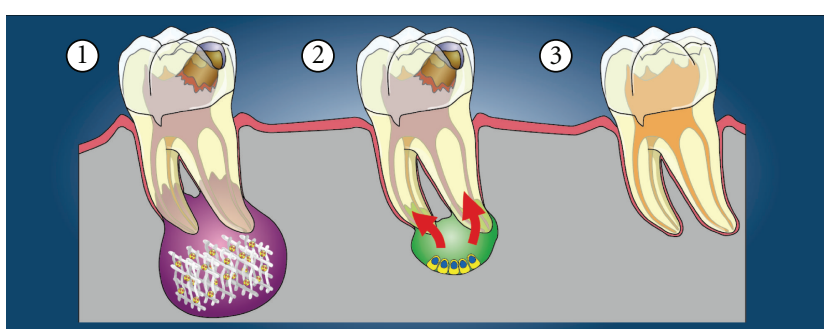

(c) Local regeneration of dentin pulp from apical pulp or periapical tissues

FIGURE 1: Strategies for regeneration of the dentin-pulp complex with three factors for tissue regeneration; growth factors, scaffolds, and cells (stem cells or progenitor cells). (a) Regeneration of the entire tooth. (b) Local regeneration of the dentin-pulp complex in the dentin defect area from residual dental pulp. (c) Local regeneration of dental pulp from apical dental pulp or periapical tissues.

2.2. Local Regeneration from Residual Dental Pulp. Local regeneration of the dentin-pulp complex from residual dental pulp has been mainly delivered by researchers who are engaged in clinical practice. Several studies have reported the use of local applications of bioactive molecules such as BMPs and recombinant fusion ameloblastin to exposed pulp [26-28]. However, local application of bioactive molecules without scaffolds only induces reparative dentin formation toward residual dental pulp, which is the same result provided by conventional therapy such as pulp capping.

Induction of appropriate pulp wound healing and formation of new dentin in dentin defects are essential for the local regeneration of the dentin-pulp complex and vital pulp therapies to form new dentin in defects. Several papers demonstrated the local regeneration of dentin-pulp complex in different methods. It was reported that BMP-4 with dentin powder induced dentinogenesis in dentin cavity with pulp exposure [29]. In this research, stem or progenitor cells were induced from residual pulp through the exposure site at the bottom of the cavity. It was also reported that ultrasound-mediated gene delivery of growth factors such as growth/differentiation factor 11 (GDF-11)/BMP-11 into dental pulp stem cells by in vivo sonoporation induced reparative dentinogenesis [30-32], and that the ex vivo gene therapy by the transplantation of pulp stem/progenitor cells 


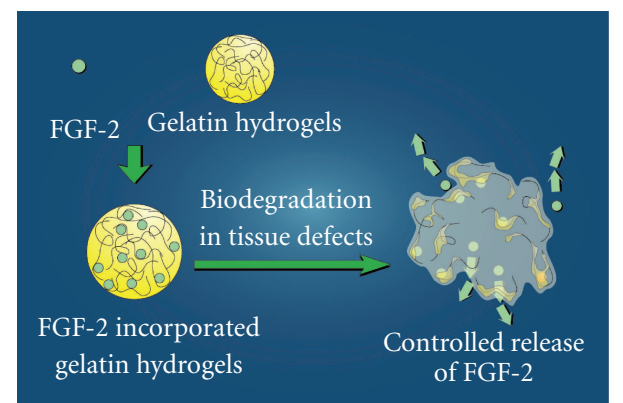

Figure 2: Controlled release of FGF-2. Gelatin hydrogels has an ability to incorporate growth factors such as FGF-2. After implantation of gelatin hydrogels incorporating FGF-2 with scaffolds, such as collagen sponge, FGF-2 is gradually released from gelatin hydrogels biodegraded by proteinase at tissue defect area. The controlled released FGF-2 can induce tissue regeneration.

transfected with some growth factors such as GDF-11/BMP11 stimulated reparative dentinogenesis [33-36].

FGF-2 is known to play a role in both physiological and pathological conditions [37-39]. It was previously demonstrated that a gradual and continual release of biologically active FGF-2 was achieved by in vivo biodegradation of gelatin hydrogels that incorporated FGF-2 [40-43] (Figure 2). Recently, we used FGF-2, gelatin hydrogels, and collagen sponge as a scaffold to induce local regeneration of rat dentin-pulp complex. We implanted free FGF-2 or gelatin hydrogels incorporating FGF-2 with collagen sponge into dentin defects above the amputated pulp of rat molars, and we found that a noncontrolled release of free FGF-2 only accelerated reparative dentin formation in the residual dental pulp, whereas a controlled release of FGF-2 from gelatin hydrogels induced formation of DMP-1-positive and nestin-negative osteodentin in the pulp proliferating in the dentin defects. Furthermore, the controlled release of an appropriate dosage of FGF-2 from gelatin hydrogels induced the formation of the dentinal bridge-like osteodentin on the surface of the regenerated pulp (Figure 3). These results suggest that our method inducing the regeneration of dentin and pulp into defect area from the amputated pulp is different from the conventional therapy that induces reparative dentinogenesis toward the amputated pulp [44, 45].

2.3. Local Regeneration from Periapical Tissues. Studies on regeneration of dental pulp from the apical area began from the identification of stem cells in the apical areas of developing teeth in which root formation is incomplete. It is suggested the existence of a new population of mesenchymal stem cells residing in the apical papilla (SCAPs) of incompletely developed teeth, and these cells have the ability to differentiate into odontoblast-like cells [46-48]. SCAPs play important roles in continued root formation, and they have been suggested to participate in pulp wound healing and regeneration. It is also known that bonemarrow-derived mesenchymal stem cells (BMMSCs) have multipotent abilities to differentiate into several cell types and undergo osteogenic differentiation. Periapical tissues include periodontal ligament, and bone marrow, which is the source of BMMSCs [49-54]. Localization of SCAPs and BMMSCs in the apical area indicate the possibility of the induction of these stem cells for the regeneration of the dentin-pulp complex.

\section{Scaffolds for Regeneration of Dentin-Pulp Complex}

It is important to select appropriate scaffolds for successful tissue regeneration. It is well known that essential properties of scaffolds are mechanical properties such as porous threedimension structure, and mechanical strength, as well as biological properties such as biocompatibility and biodegradation [55]. In recent research and clinical approach, the following biomaterials are utilized for tissue regeneration therapy; polyethylene terephthalate, poly (L-lactide-co-D, L lactide), polylactic acid, polyglycolic acid, PLGA, polyvinyl alcohol, collagen, hyaluronic acid, hydroxyapatite, tricalcium phosphate, silk fibroin, bioactive glasses, and ceramic materials [56]. Of the variety of biomaterials tested, collagen sponge has been found to be well suited for the regeneration of bone defects, as collagen is a major component of the extracellular matrix. Also in the research field of tooth regeneration therapy, several lines of studies analyzed and discussed which three-dimensional scaffolds were suitable for the regeneration of dentin-pulp complex [57-60].

Recently, we have been focusing on the application of hyaluronic acid for local regeneration of the dentin-pulp complex. Hyaluronic acid is one of the glycosaminoglycans present in the extracellular matrix and plays important roles in maintaining morphologic organization by preserving extracellular spaces, and it has been reported to have excellent potential for tissue engineering [61-65]. The roles of hyaluronic acid in some biological processes, including inhibition of inflammation and pain, and differentiation of osteoblastic and osteoclastic cells, were recently studied [66-68]. In addition, some researchers have reported that intra-articular hyaluronic acid treatment for patients with osteoarthritic knees reduced painful symptoms and improved joint mobility $[69,70]$.

Dental pulp is a type of connective tissue derived from the dental papilla, and contains large amounts of glycosaminoglycans $[71,72]$. Previously, the contribution of hyaluronic acid to the initial development of dentin matrix and dental pulp [73], in vivo application of hyaluronic acid gels on the wound healing processes of dental pulp, and the application of gelatin-chondroitin-hyaluronan tricopolymer scaffold to dental bud cells were reported [74, 75].

To clarify whether hyaluronic acid sponge (molecular weight $800 \mathrm{kDa}$ ) is useful as a scaffold for wound healing and regeneration of dental pulp, we compared in vitro and in vivo effects of hyaluronic acid sponge and collagen sponge on KN-3 odontoblast-like cell line and amputated dental pulp of rat molars. KN-3 cells, which were established from dental pulp of rat incisors, have odontoblastic properties such as high alkaline phosphatase activity and calcification ability [76]. We found that KN-3 cells adhered to both hyaluronic 


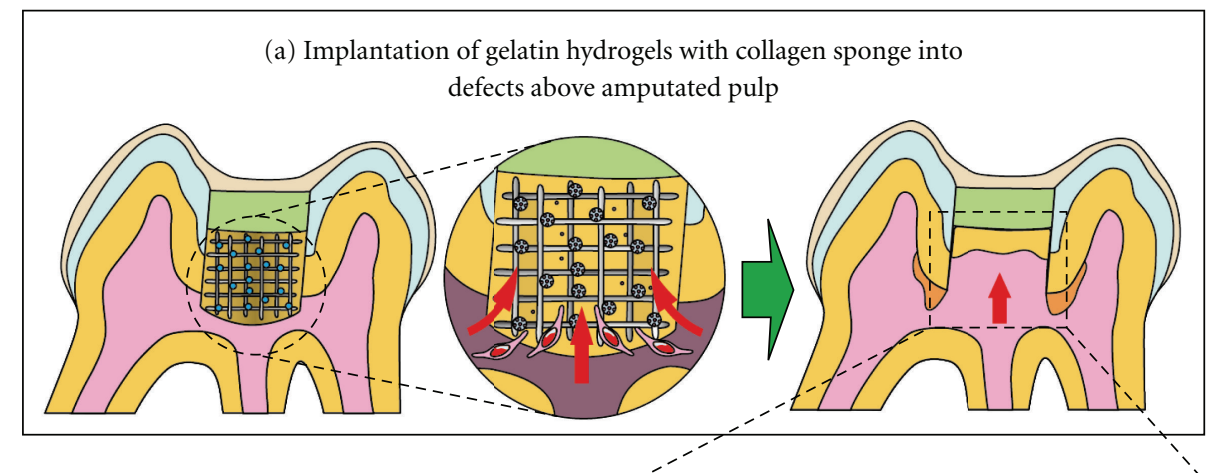

(c) Newly formed dentin at surface of proliferating pulp
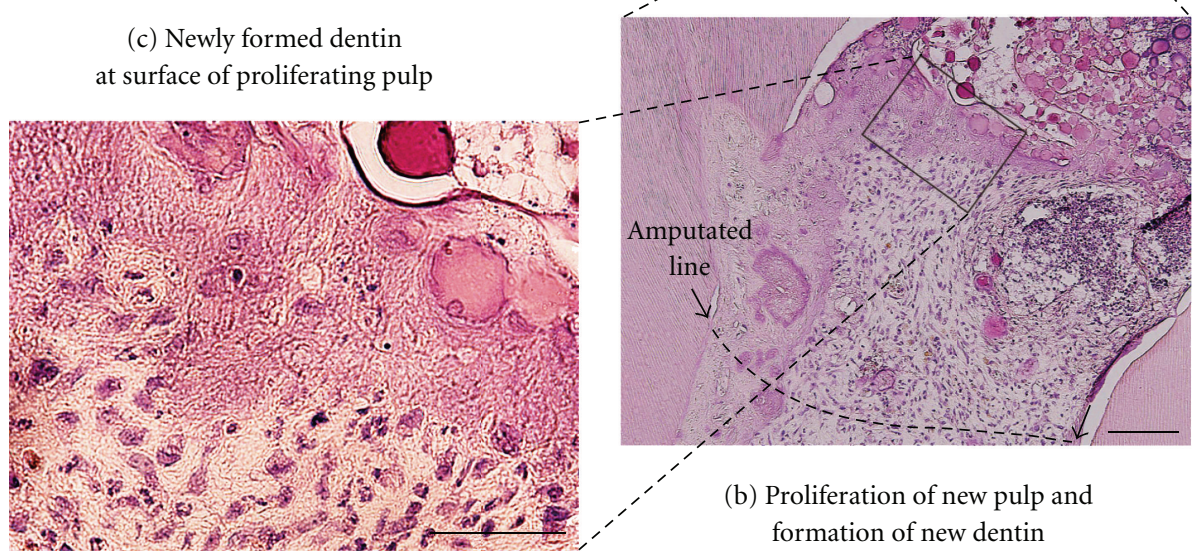

FIGURE 3: Local regeneration of the dentin-pulp complex in dentin defect area by implantation of gelatin hydrogels incorporating FGF-2. (a) Gelatin hydrogels incorporating FGF-2 with collagen sponge are implanted into dentin defect area. Controlled release of FGF-2 from biodegraded gelatin hydrogels can induce pulp stem cells or progenitor cells, as well as vessels, into collagen sponge at defect, resulting in the regeneration of pulp in the defect area and the formation of regenerative dentin on surface of the new pulp. (b) Histological photograph of proliferating pulp and newly regenerated dentin at surface of proliferating pulp. (c) High magnification of the regenerated dentin.

acid and collagen sponges during the culture period. In vivo results following implantation of both sponges in dentin defect areas above the amputated pulp showed that dental pulp proliferation and invasion of vessels into the hyaluronic acid and collagen sponges were well induced from the amputated dental pulp. These results suggest that hyaluronic acid sponge has an ability to induce and sustain dental pulp tissue regenerated from residual amputated dental pulp. In addition, we found that the inflammatory responses of $\mathrm{KN}-3$ cells and the amputated dental pulp to hyaluronic acid sponge were lower than those against collagen sponge, suggesting that hyaluronic acid sponge has biocompatibility and biodegradation characteristics as well as an appropriate structure to make it suitable as a scaffold for dental pulp regeneration [77] (Figure 4).

It is also important to clarify neuronal differentiation and neurite outgrowth during regeneration of the dentin-pulp complex. We examined the effects of hyaluronic acid gel on neuronal differentiation of PC12 pheochromocytoma cells, which respond to nerve growth factor (NGF) by extending neurites and exhibit a variety of properties of adrenal medullary chromaffin cells. We applied diluted solutions of $800 \mathrm{kDa}$ hyaluronic acid to NGF-exposed PC12 cells, and noted inhibition of NGF-induced neuronal differentiation of PC12 cells via inhibition of ERK and p38 MAPK activation, caused by the interaction of hyaluronic acid to its receptor, RHAMM [78].

Our results demonstrated that hyaluronic acid sponge is useful for local regeneration of the dentin-pulp complex, whereas hyaluronic acid gel inhibits the differentiation or neurite outgrowth of neurons. In vivo, our results showed that hyaluronic acid sponge is gradually biodegraded during the regeneration processes, leaving soluble hyaluronic acid in the regenerated dental pulp. Next, we intend to clarify the biological and physiological behaviors of hyaluronic acid throughout the regeneration the of dentin-pulp complex.

\section{Future Challenges to Achieve Local Regeneration of the Dentin-Pulp Complex}

In our strategy, growth factors and scaffolds are exogenously supplied as bioactive materials, while the source of stem cells that are able to differentiate into odontoblast-like cells and pulp cells is dependent on the residual dental pulp. The vitality of the residual dental pulp is a critical point to achieve local regeneration of the dentin-pulp complex. It is generally accepted that the pulp wound healing proceeds well under conditions of low inflammatory responses by the dental pulp. In addition, regulation of dental pulp infection is another critical point regarding the success of such regeneration 

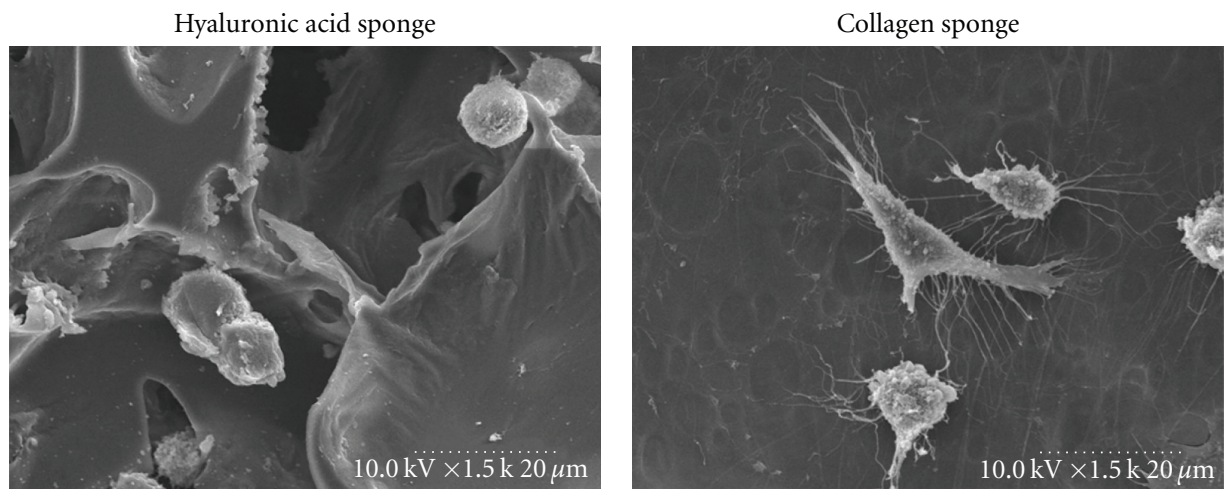

(a) Cell Adhesion on Sponges
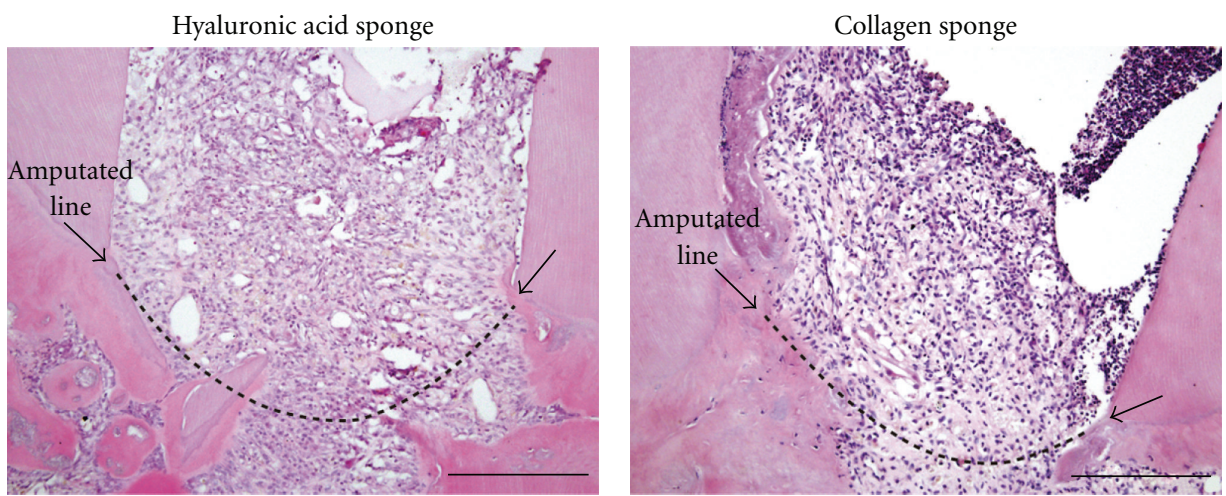

(b) Pulp proliferation and inflammatory reaction in sponges at defects

FIGURE 4: Application of hyaluronic acid sponge for local regeneration of the dentin-pulp complex. (a) KN-3 cells, odontoblastic progenitor cells, adhered to hyaluronic acid sponge, as well as collagen sponge. (b) Histological changes of amputated dental pulp after implantation of hyaluronic acid sponge in vivo. Amputated dental pulp well proliferated into hyaluronic acid and collagen sponges. Compared with collagen sponge, hyaluronic acid sponge significantly suppressed inflammatory reaction of dental pulp.

therapy. The resin bonding system is commonly used as one of materials showing favorable adhesion to enamel and dentin, and composite resin system with antimicrobial ability was reported [79-81]. These restorative materials may inhibit further bacterial invasion after tissue regeneration of dentin-pulp complex. Furthermore, when we try to induce revascularization and SCAPs and BMMSCs from the apical area into scaffolds at the root canal to regenerate dentinpulp complex, disinfection of infected root canal systems, as well as proper apical enlargement to permit the induction from periapical tissues, should be successfully established [82]. Local regeneration of the dentin-pulp complex will be accomplished when the regulation mechanisms of pulp inflammation and infection, as well as pulp wound healing and regeneration mechanisms, are clarified.

\section{References}

[1] C. Kitamura, K. Kimura, T. Nakayama, K. Toyoshima, and M. Terashita, "Primary and secondary induction of apoptosis in odontoblasts after cavity preparation of rat molars," Journal of Dental Research, vol. 80, no. 6, pp. 1530-1534, 2001.

[2] C. Kitamura, Y. Ogawa, T. Nishihara, T. Morotomi, and M. Terashita, "Transient co-localization of c-Jun N-terminal kinase and c-Jun with heat shock protein 70 in pulp cells during apoptosis," Journal of Dental Research, vol. 82, no. 2, pp. 91-95, 2003.

[3] C. Kitamura, T. Nishihara, Y. Ueno, M. Nagayoshi, S. Kasugai, and M. Terashita, "Thermotolerance of pulp cells and phagocytosis of apoptotic pulp cells by surviving pulp cells following heat stress," Journal of Cellular Biochemistry, vol. 94, no. 4, pp. 826-834, 2005.

[4] C. Kitamura, T. Nishihara, Y. Ueno et al., "Effects of sequential exposure to lipopolysaccharide and heat stress on dental pulp cells," Journal of Cellular Biochemistry, vol. 99, no. 3, pp. 797$806,2006$.

[5] Y. Ueno, C. Kitamura, M. Terashita, and T. Nishihara, "Re-oxygenation improves hypoxia-induced pulp cell arrest," Journal of Dental Research, vol. 85, no. 9, pp. 824-828, 2006.

[6] A. J. Smith, N. Cassidy, H. Perry, C. Bègue-Kirn, J. V. Ruch, and H. Lesot, "Reactionary dentinogenesis," International Journal of Developmental Biology, vol. 39, no. 1, pp. 273-280, 1995.

[7] T. A. Mitsiadis, K. Fried, and C. Goridis, "Reactivation of Delta-Notch signaling after injury: complementary expression patterns of ligand and receptor in dental pulp," Experimental Cell Research, vol. 246, no. 2, pp. 312-318, 1999.

[8] E. Kawagishi, K. Nakakura-Ohshima, S. Nomura, and H. Ohshima, "Pulpal responses to cavity preparation in aged rat molars," Cell and Tissue Research, vol. 326, no. 1, pp. 111-122, 2006.

[9] J. P. van Nieuwenhuysen, M. Aouar, and W. D'Hoore, "Retreatment or radiographic monitoring in endodontics," 
International Endodontic Journal, vol. 27, no. 2, pp. 75-81, 1994.

[10] I. Rotstein, R. Salehrabi, and J. L. Forrest, "Endodontic treatment outcome: survey of oral health care professionals," Journal of Endodontics, vol. 32, no. 5, pp. 399-403, 2006.

[11] N. Imura, E. T. Pinheiro, B. P. F. A. Gomes, A. A. Zaia, C. C. R. Ferraz, and F. J. Souza-Filho, "The outcome of endodontic treatment: a retrospective study of 2000 cases performed by a specialist," Journal of Endodontics, vol. 33, no. 11, pp. 1278 1282, 2007.

[12] Y. L. Ng, V. Mann, and K. Gulabivala, "Outcome of secondary root canal treatment: a systematic review of the literature," International Endodontic Journal, vol. 41, no. 12, pp. 10261046, 2008.

[13] D. E. Discher, D. J. Mooney, and P. W. Zandstra, "Growth factors, matrices, and forces combine and control stem cells," Science, vol. 324, no. 5935, pp. 1673-1677, 2009.

[14] P. C. Yelick and J. P. Vacanti, "Bioengineered teeth from tooth bud cells," Dental Clinics of North America, vol. 50, no. 2, pp. 191-203, 2006.

[15] S. E. Duailibi, M. T. Duailibi, W. Zhang, R. Asrican, J. P. Vacanti, and P. C. Yelick, "Bioengineered dental tissues grown in the rat jaw," Journal of Dental Research, vol. 87, no. 8, pp. 745-750, 2008.

[16] M. T. Duailibi, S. E. Duailibi, C. S. Young, J. D. Bartlett, J. P. Vacanti, and P. C. Yelick, "Bioengineered teeth from cultured rat tooth bud cells," Journal of Dental Research, vol. 83, no. 7, pp. 523-528, 2004.

[17] M. J. Honda, Y. Sumita, H. Kagami, and M. Ueda, "Histological and immunohistochemical studies of tissue engineered odontogenesis," Archives of Histology and Cytology, vol. 68, no. 2, pp. 89-101, 2005.

[18] Y. Sumita, M. J. Honda, T. Ohara et al., "Performance of collagen sponge as a 3-D scaffold for tooth-tissue engineering," Biomaterials, vol. 27, no. 17, pp. 3238-3248, 2006.

[19] M. Honda, N. Morikawa, K. Hata et al., "Rat costochondral cell characteristics on poly (L-lactide-co- $\varepsilon$-caprolactone) scaffolds," Biomaterials, vol. 24, no. 20, pp. 3511-3519, 2003.

[20] L. Zheng, F. Yang, H. Shen et al., "The effect of composition of calcium phosphate composite scaffolds on the formation of tooth tissue from human dental pulp stem cells," Biomaterials, vol. 32, no. 29, pp. 7053-7059, 2011.

[21] Z. Yuan, H. Nie, S. Wang et al., "Biomaterial selection for tooth regeneration," Tissue Engineering Part B. vol. 17, no. 5, pp. 373-388, 2011.

[22] K. Nakao, R. Morita, Y. Saji et al., "The development of a bioengineered organ germ method," Nature Methods, vol. 4, no. 3, pp. 227-230, 2007.

[23] K. Ishida, M. Murofushi, K. Nakao, R. Morita, M. Ogawa, and T. Tsuji, "The regulation of tooth morphogenesis is associated with epithelial cell proliferation and the expression of Sonic hedgehog through epithelial-mesenchymal interactions," Biochemical and Biophysical Research Communications, vol. 405, no. 3, pp. 455-461, 2011.

[24] E. Ikeda, R. Morita, K. Nakao et al., "Fully functional bioengineered tooth replacement as an organ replacement therapy," Proceedings of the National Academy of Sciences of the United States of America, vol. 106, no. 32, pp. 13475-13480, 2009.

[25] E. Ikeda and T. Tsuji, "Growing bioengineered teeth from single cells: potential for dental regenerative medicine," Expert Opinion on Biological Therapy, vol. 8, no. 6, pp. 735-744, 2008.
[26] R. B. Rutherford and K. Gu, "Treatment of inflamed ferret dental pulps with recombinant bone morphogenetic protein7," European Journal of Oral Sciences, vol. 108, no. 3, pp. 202206, 2000.

[27] N. Six, J. J. Lasfargues, and M. Goldberg, "Differential repair responses in the coronal and radicular areas of the exposed rat molar pulp induced by recombinant human bone morphogenetic protein 7 (osteogenic protein 1)," Archives of Oral Biology, vol. 47, no. 3, pp. 177-187, 2002.

[28] Y. Nakamura, I. Slaby, A. Spahr, G. Pezeshki, K. Matsumoto, and S. P. Lyngstadaas, "Ameloblastin fusion protein enhances pulpal healing and dentin formation in porcine teeth," Calcified Tissue International, vol. 78, no. 5, pp. 278-284, 2006.

[29] M. Nakashima, "Induction of dentin formation on canine amputated pulp by recombinant human bone morphogenetic proteins (BMP)-2 and -4," Journal of Dental Research, vol. 73, no. 9, pp. 1515-1522, 1994.

[30] M. Nakashima, K. Tachibana, K. Iohara, M. Ito, M. Ishikawa, and A. Akamine, "Induction of reparative dentin formation by ultrasound-mediated gene delivery of growth/differentiation factor 11," Human Gene Therapy, vol. 14, no. 6, pp. 591-597, 2003.

[31] M. Nakashima, K. Iohara, M. Ishikawa et al., "Stimulation of reparative dentin formation by ex vivo gene therapy using dental pulp stem cells electrotransfected with growth/differentiation factor 11 (Gdf11)," Human Gene Therapy, vol. 15, no. 11, pp. 1045-1053, 2004.

[32] M. Nakashima, K. Mizunuma, T. Murakami, and A. Akamine, "Induction of dental pulp stem cell differentiation into odontoblasts by electroporation-mediated gene delivery of growth/differentiation factor 11 (Gdf11)," Gene Therapy, vol. 9, no. 12, pp. 814-818, 2002.

[33] K. Iohara, M. Nakashima, M. Ito, M. Ishikawa, A. Nakasima, and A. Akamine, "Dentin regeneration by dental pulp stem cell therapy with recombinant human bone morphogenetic protein 2," Journal of Dental Research, vol. 83, no. 8, pp. 590595, 2004.

[34] M. Nakashima, K. Iohara, and L. Zheng, "Gene therapy for dentin regeneration with bone morphogenetic proteins," Current Gene Therapy, vol. 6, no. 5, pp. 551-560, 2006.

[35] K. Iohara, L. Zheng, M. Ito et al., "Regeneration of dental pulp after pulpotomy by transplantation of $\mathrm{CD} 31^{-} / \mathrm{CD} 146^{-}$side population cells from a canine tooth," Regenerative Medicine, vol. 4, no. 3, pp. 377-385, 2009.

[36] M. Nakashima, "Tissue engineering in endodontics," Australian Endodontic Journal, vol. 31, no. 3, pp. 111-113, 2005.

[37] T. Tsuboi, S. Mizutani, M. Nakano, K. Hirukawa, and A. Togari, "FGF-2 regulates enamel and dentine formation in mouse tooth germ," Calcified Tissue International, vol. 73, no. 5, pp. 496-501, 2003.

[38] A. K. Madan and B. Kramer, "Immunolocalization of fibroblast growth factor-2 (FGF-2) in the developing root and supporting structures of the murine tooth," Journal of Molecular Histology, vol. 36, no. 3, pp. 171-178, 2005.

[39] L. Tran-Hung, S. Mathieu, and I. About, "Role of human pulp fibroblasts in angiogenesis," Journal of Dental Research, vol. 85, no. 9, pp. 819-823, 2006.

[40] Y. Tabata and Y. Ikada, "Vascularization effect of basic fibroblast growth factor released from gelatin hydrogels with different biodegradabilities," Biomaterials, vol. 20, no. 22, pp. 2169-2175, 1999.

[41] Y. Tabata, M. Miyao, T. Inamoto et al., "De novo formation of adipose tissue by controlled release of basic fibroblast growth factor," Tissue Engineering, vol. 6, no. 3, pp. 279-289, 2000. 
[42] Y. Tabata, A. Nagano, Y. Ikada, and Y. Ikada, "Biodegradation of hydrogel carrier incorporating fibroblast growth factor," Tissue Engineering, vol. 5, no. 2, pp. 127-138, 1999.

[43] M. Yamamoto, Y. Ikada, and Y. Tabata, "Controlled release of growth factors based on biodegradation of gelatin hydrogel," Journal of Biomaterials Science, Polymer Edition, vol. 12, no. 1, pp. 77-88, 2001.

[44] N. Kikuchi, C. Kitamura, T. Morotomi et al., "Formation of dentin-like particles in dentin defects above exposed pulp by controlled release of fibroblast growth factor 2 from gelatin hydrogels," Journal of Endodontics, vol. 33, no. 10, pp. 11981202, 2007.

[45] H. Ishimatsu, C. Kitamura, T. Morotomi et al., "Formation of dentinal bridge on surface of regenerated dental pulp in dentin defects by controlled release of fibroblast growth factor- 2 from gelatin hydrogels," Journal of Endodontics, vol. 35, no. 6, pp. 858-865, 2009.

[46] W. Sonoyama, Y. Liu, D. Fang et al., "Mesenchymal stem cellmediated functional tooth regeneration in Swine," PLOS ONE, vol. 1, no. 1, p. e79, 2006.

[47] W. Sonoyama, Y. Liu, T. Yamaza et al., "Characterization of the apical papilla and its residing stem cells from human immature permanent teeth: a pilot study," Journal of Endodontics, vol. 34, no. 2, pp. 166-171, 2008.

[48] G. T. J. Huang, W. Sonoyama, Y. Liu, H. Liu, S. Wang, and S. Shi, "The hidden treasure in apical papilla: the potential role in pulp/dentin regeneration and bioroot engineering," Journal of Endodontics, vol. 34, no. 6, pp. 645-651, 2008.

[49] R. Ebert, S. Zeck, R. Krug et al., "Pulse treatment with zoledronic acid causes sustained commitment of bone marrow derived mesenchymal stem cells for osteogenic differentiation," Bone, vol. 44, no. 5, pp. 858-864, 2009.

[50] B. M. Abdallah and M. Kassem, "The use of mesenchymal (skeletal) stem cells for treatment of degenerative diseases: current status and future perspectives," Journal of Cellular Physiology, vol. 218, no. 1, pp. 9-12, 2009.

[51] T. Y. Lim, W. Wang, Z. Shi, C. K. Poh, and K. G. Neoh, "Human bone marrow-derived mesenchymal stem cells and osteoblast differentiation on titanium with surface-grafted chitosan and immobilized bone morphogenetic protein-2," Journal of Materials Science: Materials in Medicine, vol. 20, no. 1, pp. 1-10, 2009.

[52] X. C. Wan, C. P. Liu, M. Li et al., "Staphylococcal enterotoxin $\mathrm{C}$ injection in combination with ascorbic acid promotes the differentiation of bone marrow-derived mesenchymal stem cells into osteoblasts in vitro," Biochemical and Biophysical Research Communications, vol. 373, no. 4, pp. 488-492, 2008.

[53] S. Post, B. M. Abdallah, J. F. Bentzon, and M. Kassem, "Demonstration of the presence of independent preosteoblastic and pre-adipocytic cell populations in bone marrow-derived mesenchymal stem cells," Bone, vol. 43, no. 1, pp. 32-39, 2008.

[54] K. Lavery, P. Swain, D. Falb, and M. H. Alaoui-Ismaili, "BMP-2/4 and BMP-6/7 differentially utilize cell surface receptors to induce osteoblastic differentiation of human bone marrow-derived mesenchymal stem cells," Journal of Biological Chemistry, vol. 283, no. 30, pp. 20948-20958, 2008.

[55] M. Horst, S. Madduri, R. Gobet, T. Sulser, H. Hall, and D. Eberli, "Scaffold characteristics for functional hollow organ regeneration," Materials, vol. 3, no. 1, pp. 241-263, 2010.

[56] S. Sundelacruz and D. L. Kaplan, "Stem cell- and scaffoldbased tissue engineering approaches to osteochondral regenerative medicine," Seminars in Cell and Developmental Biology, vol. 20, no. 6, pp. 646-655, 2009.
[57] M. M. Cordeiro, Z. Dong, T. Kaneko et al., "Dental pulp tissue engineering with stem cells from exfoliated deciduous teeth," Journal of Endodontics, vol. 34, no. 8, pp. 962-969, 2008.

[58] J. Y. Kim, X. Xin, E. K. Moioli et al., "Regeneration of dentalpulp-like tissue by chemotaxis-induced cell homing," Tissue Engineering Part A, vol. 16, no. 10, pp. 3023-3031, 2010.

[59] S. Chandrahasa, P. E. Murray, and K. N. Namerow, "Proliferation of mature ex vivo human dental pulp using tissue engineering scaffolds," Journal of Endodontics, vol. 37, no. 9, pp. 1236-1239, 2011.

[60] F. Garcia-Godoy and P. E. Murray, "Recommendations for using regenerative endodontic procedures in permanent immature traumatized teeth," Dental Traumatology. In press.

[61] P. Angele, R. Kujat, M. Nerlich, J. Yoo, V. Goldberg, and B. Johnstone, "Engineering of osteochondral tissue with bone marrow mesenchymal progenitor cells in a derivatized hyaluronan-gelatin composite sponge," Tissue Engineering, vol. 5 , no. 6, pp. 545-554, 1999.

[62] A. Ramamurthi and I. Vesely, "Smooth muscle cell adhesion on crosslinked hyaluronan gels," Journal of Biomedical Materials Research, vol. 60, no. 1, pp. 196-205, 2002.

[63] Y. Liu, X. Z. Shu, S. D. Gray, and G. D. Prestwich, "Disulfidecrosslinked hyaluronan-gelatin sponge: growth of fibrous tissue in vivo," Journal of Biomedical Materials Research Part A, vol. 68, no. 1, pp. 142-149, 2004.

[64] H. D. Kim and R. F. Valentini, "Retention and activity of BMP-2 in hyaluronic acid-based scaffolds in vitro," Journal of Biomedical Materials Research, vol. 59, no. 3, pp. 573-584, 2002.

[65] R. A. Peattie, A. P. Nayate, M. A. Firpo, J. Shelby, R. J. Fisher, and G. D. Prestwich, "Stimulation of in vivo angiogenesis by cytokine-loaded hyaluronic acid hydrogel implants," Biomaterials, vol. 25, no. 14, pp. 2789-2798, 2004.

[66] J. R. E. Fraser, T. C. Laurent, and U. B. G. Laurent, "Hyaluronan: its nature, distribution, functions and turnover," Journal of Internal Medicine, vol. 242, no. 1, pp. 27-33, 1997.

[67] G. P. Dowthwaite, J. C. W. Edwards, and A. A. Pitsillides, "An essential role for the interaction between hyaluronan and hyaluronan binding proteins during joint development," Journal of Histochemistry and Cytochemistry, vol. 46, no. 5, pp. 641-651, 1998.

[68] A. J. Day and J. K. Sheehan, "Hyaluronan: polysaccharide chaos to protein organisation," Current Opinion in Structural Biology, vol. 11, no. 5, pp. 617-622, 2001.

[69] T. J. Liesegang, "Viscoelastic substances in ophthalmology," Survey of Ophthalmology, vol. 34, no. 4, pp. 268-293, 1990.

[70] K. Fukuda, H. Dan, M. Takayama, F. Kumano, M. Saitoh, and S. Tanaka, "Hyaluronic acid increases proteoglycan synthesis in bovine articular cartilage in the presence of interleukin-1," Journal of Pharmacology and Experimental Therapeutics, vol. 277, no. 3, pp. 1672-1675, 1996.

[71] A. Linde, "A study of the dental pulp glycosaminoglycans from permanent human teeth and rat and rabbit incisors," Archives of Oral Biology, vol. 18, no. 1, pp. 49-59, 1973.

[72] N. Sakamoto, H. Okamoto, and K. Okuda, "Qualitative and quantitative analyses of bovine, rabbit and human dental pulp glycosaminoglycans," Journal of Dental Research, vol. 58, no. 2, pp. 646-655, 1979.

[73] S. Felszeghy, M. Hyttinen, R. Tammi, M. Tammi, and L. Módis, "Quantitative image analysis of hyaluronan expression in human tooth germs," European Journal of Oral Sciences, vol. 108, no. 4, pp. 320-326, 2000.

[74] T. Sasaki and H. Kawamata-Kido, "Providing an environment for reparative dentine induction in amputated rat molar pulp 
by high molecular-weight hyaluronic acid," Archives of Oral Biology, vol. 40, no. 3, pp. 209-219, 1995.

[75] T. F. Kuo, A. T. Huang, H. H. Chang et al., "Regeneration of dentin-pulp complex with cementum and periodontal ligament formation using dental bud cells in gelatin-chondroitinhyaluronan tri-copolymer scaffold in swine," Journal of Biomedical Materials Research Part A, vol. 86, no. 4, pp. 10621068, 2008.

[76] K. Nomiyama, C. Kitamura, T. Tsujisawa et al., "Effects of lipopolysaccharide on newly established rat dental pulpderived cell line with odontoblastic properties," Journal of Endodontics, vol. 33, no. 10, pp. 1187-1191, 2007.

[77] Y. Inuyama, C. Kitamura, T. Nishihara et al., "Effects of hyaluronic acid sponge as a scaffold on odontoblastic cell line and amputated dental pulp," Journal of Biomedical Materials Research Part B, vol. 92, no. 1, pp. 120-128, 2010.

[78] A. Washio, C. Kitamura, E. Jimi, M. Terashita, and T. Nishihara, "Mechanisms involved in suppression of NGFinduced neuronal differentiation of PC12 cells by hyaluronic acid," Experimental Cell Research, vol. 315, no. 17, pp. 30363043, 2009.

[79] N. Izutani, S. Imazato, K. Nakajo et al., "Effects of the antibacterial monomer 12-methacryloyloxydodecylpyridinium bromide (MDPB) on bacterial viability and metabolism," European Journal of Oral Sciences, vol. 119, no. 2, pp. 175-181, 2011.

[80] S. Imazato, "Bio-active restorative materials with antibacterial effects: new dimension of innovation in restorative dentistry," Dental Materials Journal, vol. 28, no. 1, pp. 11-19, 2009.

[81] S. Imazato, F. R. Tay, A. V. Kaneshiro, Y. Takahashi, and S. Ebisu, "An in vivo evaluation of bonding ability of comprehensive antibacterial adhesive system incorporating MDPB," Dental Materials, vol. 23, no. 2, pp. 170-176, 2007.

[82] P. E. Murray, F. Garcia-Godoy, and K. M. Hargreaves, "Regenerative endodontics: a review of current status and a call for action," Journal of Endodontics, vol. 33, no. 11, p. 1277, 2007. 


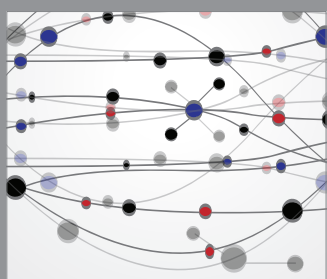

The Scientific World Journal
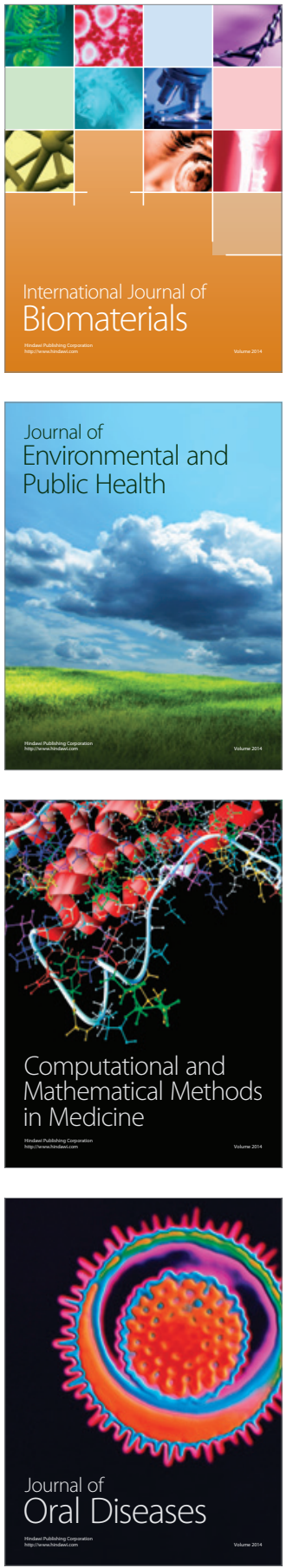
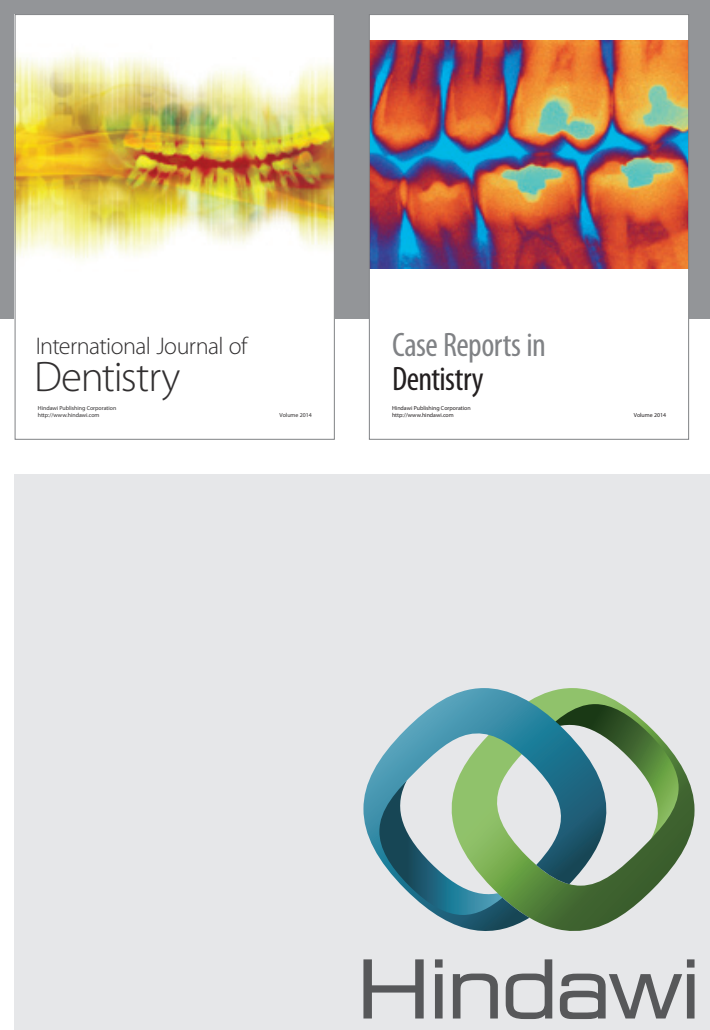

Submit your manuscripts at

http://www.hindawi.com
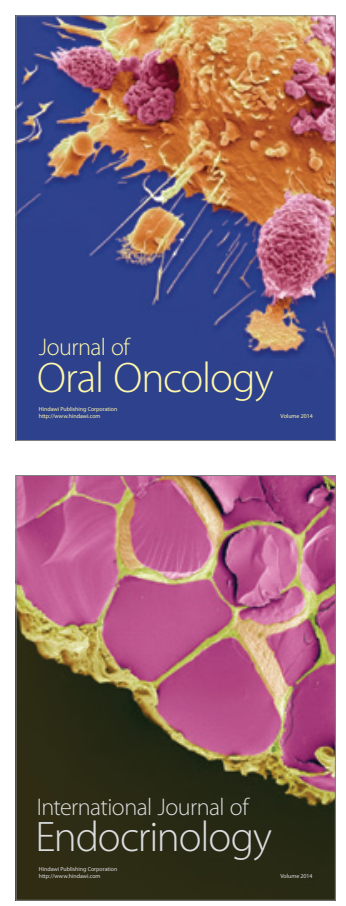
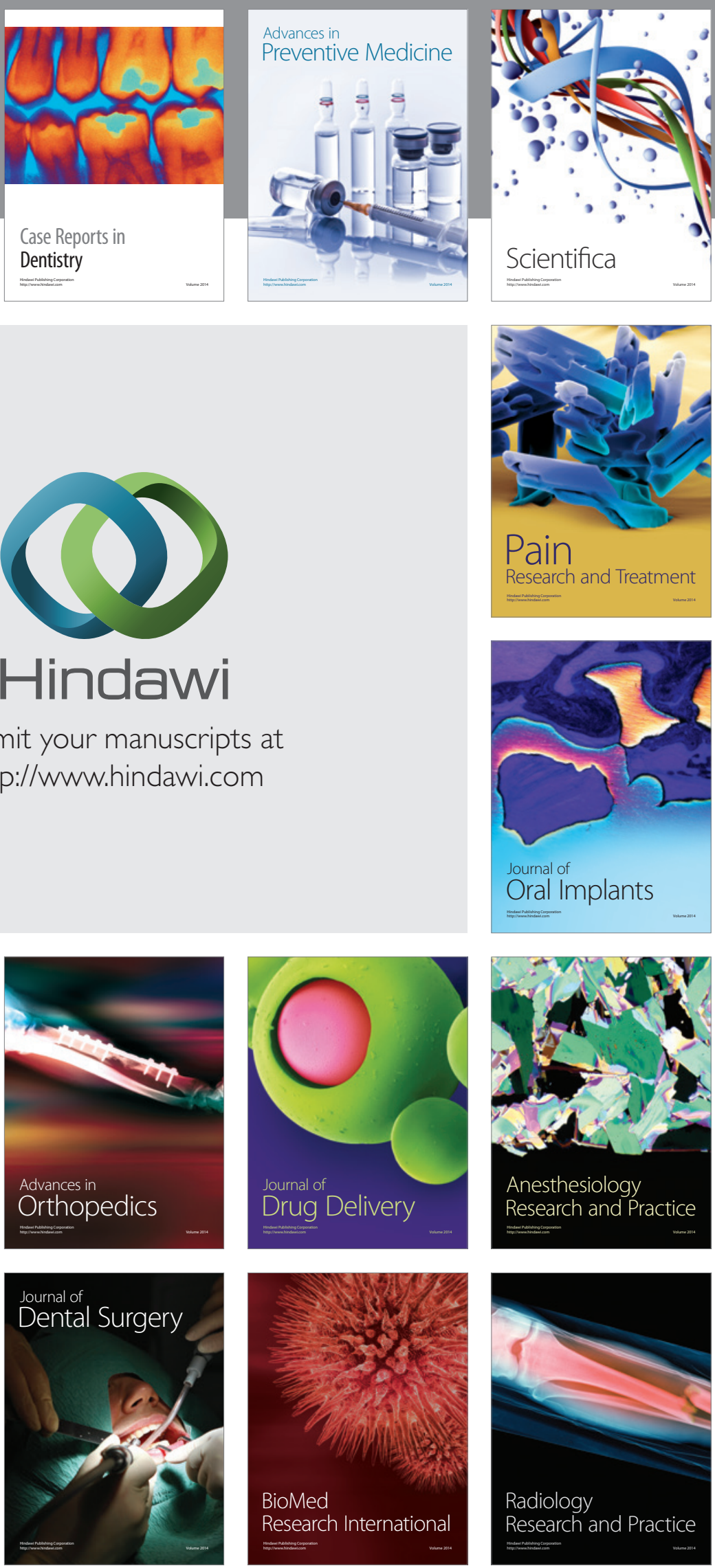